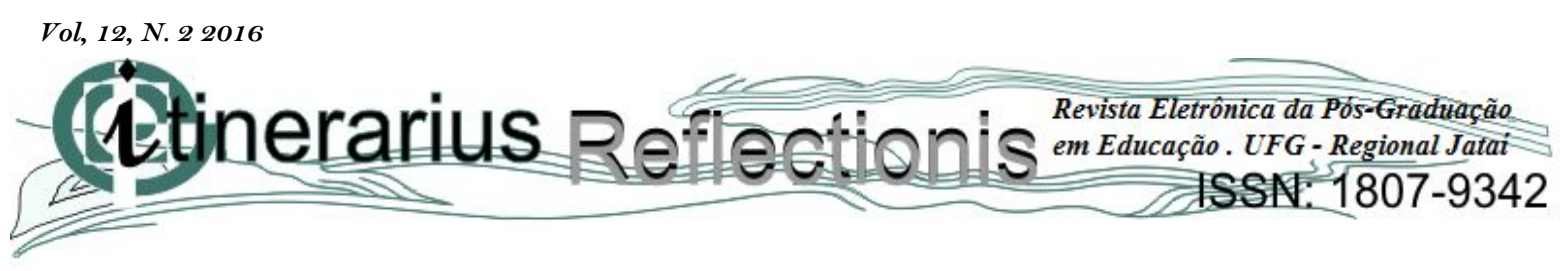

\title{
CONHECENDO A ANATOMIA: \\ A integração da Universidade com a educação básica
}

\author{
Carla Helrigle Silva, \\ Cássio Aparecido Pereira Fontana, \\ Luciano Fernades da Silva, \\ Guilherme Rezende Ramos, \\ Paulo Fernando Zaiden Rezende, \\ Ana Lúcia Rezende Souza
}

\begin{abstract}
RESUMO: O conceito de qualidade da educação é uma meta a ser conquistada. Uma boa proposta pedagógica faz com que o dever de ensinar seja assumido por todos até como efetivação do princípio da gestão democrática. Visitar um Laboratório de Anatomia pode facilitar a compreensão dos conteúdos de anatomia e ciências, ministrados no ensino fundamental e médio, despertando uma possível escolha profissional. O Laboratório de Anatomia da Universidade Federal de Goiás/Regional Jataí é composto pelas áreas de Veterinária, Humana e Comparada, além de um Museu do Cerrado. Nele há peças que compõem o acervo das aulas e em exposição no museu. Com a visita, os alunos podem vivenciar na prática aquilo que é ministrado em sala de aula, permitindo abrir espaços para discussões e sanar dúvidas sobre o conteúdo visto apenas na teoria; além de poder despertar interesse sobre os cursos oferecidos na instituição e contato com profissionais formados nas áreas das Ciências da Saúde e Ciências Agrárias. Através de questionário é possível verificar o impacto da visita no aprendizado e escolha profissional. No período de setembro de 2014 a junho de 2015, tivemos a visita de quatro escolas, totalizando 173 alunos de ambos os sexos, com idade de 12 a 14 anos, cursando o $7^{\circ}$ e $8^{\circ}$ anos, os quais responderam nossos questionários, que buscavam verificar as perspectivas futuras do aluno secundarista no seu aprendizado e em sua escolha profissional na universidade e qual a influência da visita ao laboratório em seu conhecimento. Foi verificado um pouco do cenário atual da educação no sentido da prática nas escolas, onde $66,4 \%$ dos alunos nunca haviam visitado nenhuma outra instituição de ensino além da qual estudavam, sendo que mesmo em escolas públicas o percentual chegou a $67,82 \%$. Também sobre as perguntas do questionário, $60 \%$ dos alunos demonstraram que a visita veio esclarecer dúvidas pessoais sobre o conteúdo administrado nas suas respectivas escolas, destes 56\% tinham alguma escolha profissional. A universidade deve socializar o seu espaço para auxiliar uma melhor qualidade na educação fundamental e ensino médio.
\end{abstract}

Palavras-chave: Anatomia, Conhecimento, Educação.

\section{GETTING TO KNOW ANATOMY: THE INTEGRATION OF UNIVERSITY WITH BASIC EDUCATION}

\begin{abstract}
The concept of quality of education is a goal to be achieved. A good pedagogical proposal makes the duty of teaching to be assumed by all as the implementation of the principle of democratic management. Visiting an Anatomy Laboratory can facilitate the understanding of the anatomy and sciences contents, taught in elementary and high schools, raising a possible career choice. The Anatomy Laboratory of the Federal University of Goiás / Campus of Jataí is composed of Veterinary Medicine, Human and Comparative areas, and a Cerrado Museum. There are pieces that
\end{abstract}


make up the collection of classes and on display in the museum. With the visit, students can experience in practice what is taught in classroom, allowing open spaces for discussion and answer questions about contents only seen in theory; besides being able to arise interest in the courses offered at the institution and contact with professionals trained in the areas of Health Sciences and Agricultural Sciences. Through the questionnaire, it is possible to check the impact of the visit on learning and career choice. From September 2014 to June 2015, the laboratory was visited by students from four schools, totaling 173 students of both sexes aged 12-14, attending the $7^{\text {th }}$ and $8^{\text {th }}$ grades, who answered our questionnaire, which sought to verify the future prospects of high-school students in their learning and professional choice at the university and the influence of the visit to the laboratory on their knowledge. Some of the current scenario of education towards the practice in schools was found, where $66.4 \%$ of students had never visited any other educational institution, and in public schools, this percentage was $67.82 \%$. Also regarding the questionnaire questions, $60 \%$ of students demonstrated that the visit came to clarify personal questions about contents taught in their schools, and of these, $56 \%$ had some professional choice. The university should socialize its space to support a better quality in elementary and high school.

Keywords: Education, Anatomy, Knowledge.

\section{INTRODUÇÃO}

Desde a década de noventa que o ensino de Ciências introduziu e ampliou o uso de novos materiais e diversas metodologias, para trabalhar em sala de aula, buscando a formação de um cidadão crítico e criativo (BORGES, 2000).

Ensinar conceitos apenas por palavras pode ser um verbalismo vazio quando se coloca no lugar da palavra desconhecida outra palavra igualmente incompreensível (VIGOTSKY, 2000).

Na construção de significados para um determinado conteúdo, os modelos didáticos e as aulas práticas favorecem a elaboração e expressão de conceitos, e ainda podem funcionar como meios educacionais fundamentais de comunicação entre professor e alunos. A apresentação de conteúdos potencialmente significativos, de maneira que o sujeito possa relacioná-los com suas próprias ideias, viabilizam a aprendizagem, mas também exigem disposição, atitude ativa e motivação desse sujeito para a aprendizagem (MADRUGA, 1996).

Uma disciplina não deveria ser desenvolvida apenas de forma teórica, mas sempre apoiada em um conjunto de aulas práticas que aprimorem os conceitos transformando-os em conhecimentos científicos (CRUZ, LEITE, ORECCHIO et al, 1996).

É de fundamental importância para o ensino, as aulas práticas de laboratório, pois permitem ao aluno o contato direto com o material, podendo observar, manipular e pesquisar 


\section{Vol, 12, N. 22016}

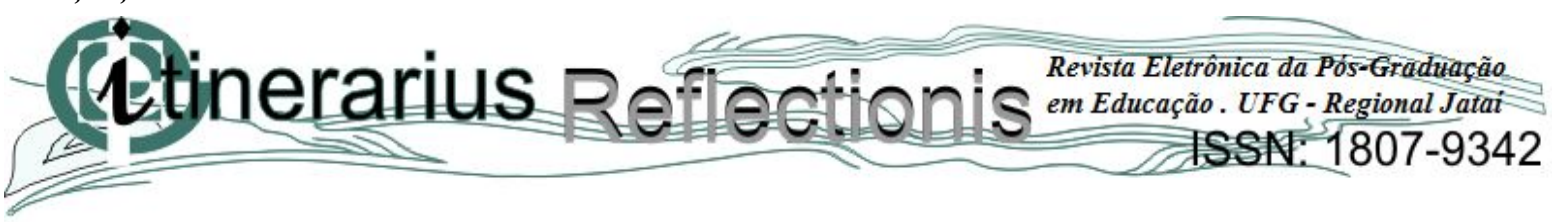

sobre a temática estudada (KRASILCHICK, 2004). O ensino do corpo humano é fundamental na formação do aluno, visto que é de suma importância se conhecer e compreender a complexidade do seu próprio organismo (SILVA, 2007; OLIVEIRA, 2011). Este assunto é contemplado na Educação Básica, no entanto, as escolas da rede de ensino Público ou Privado não dispõem de laboratório de anatomia humana para atender esse componente (EVARISTO et al. 2013).

No ensino médio, de modo geral, o ensino de Biologia ainda é marcado pela predominância de aulas expositivas como modalidade didática. Essa modalidade tende a não motivar e valorizar a participação efetiva dos alunos nas atividades de sala de aula (ZUANON e DINIZ, 2004).

Segundo Molinari et al. (1999) e Melo et al. (2002), a diversidade do material pedagógico facilita o aprendizado, tornando as aulas práticas mais dinâmicas e produtivas. No entanto, a maioria das escolas apresenta escassez de material biológico, para realização de aulas práticas. A utilização de um recurso demonstrativo estimula o aprendiz numa aula teórico-prática, tornando o processo de ensino-aprendizagem mais eficaz e interessante.

A extensão como prática pedagógica de ensino pode acelerar a distância do tempo entre o conhecimento produzido e o conhecimento apropriado pelo cidadão. A interação com a comunidade contribui para que cada profissional se torne socialmente ativo e, sobretudo, um educador cidadão (FERREIRA, 2005).

O conceito de qualidade da educação, em suas diferentes dimensões, é uma meta a ser conquistada. Para que se possa avançar nessa qualidade no Brasil atual uma particular ênfase é dada à ideia de implantação de uma Lei de Responsabilidade Educacional, que poderia ter impacto altamente significativo na forma como as questões educacionais são tratadas em nosso país (CURY, 2010).

Nos indicadores de qualidade geral existem dois grandes grupos de variáveis. As variáveis de estrutura que dizem respeito às características físicas e ambientais e o desempenho das pessoas que nelas atuam. As variáveis de processo incluem as interações das crianças com os adultos e aos seus iguais (ROSSBACH, CLIFFORD E HARMS, 1991; TIETZE, LEAL E ROSSBACH, 1998). 
Considerando que um contexto educativo de qualidade é aquele que pode ter impacto positivo no desenvolvimento das crianças (Ministério da Educação, 2000; CRYER, 1999). Uma boa proposta pedagógica faz com que o dever de ensinar, em vista do aprendizado qualificado, seja assumido por todos até como efetivação do princípio da gestão democrática (CURY, 2010). De modo mais abrangente, considera que "ensinar é negociar significados" (TEIXEIRA, 2004).

A extensão universitária possibilita uma troca de conhecimentos com a comunidade, em que usa sua estrutura levando conhecimento e assistência e trazendo melhorias através do saber popular (SCHEIDEMANTEl et al. 2004). E para Tabolka \& Grotto (2012) as atividades de extensão permitem a possibilidade de comunicação/divulgação dos conhecimentos produzidos nas universidades a uma parcela mais ampla da sociedade.

A necessidade de popularização do conhecimento e a responsabilidade social da universidade em transpor os seus muros, oportuniza para a comunidade o acesso ao conhecimento produzido em seus limites institucionais.

A estrutura física e o acervo do Laboratório de Anatomia permitem que esta proposta seja executada, atendendo a formação não só dos alunos da graduação da Regional Jataí, mas também dos alunos do ensino fundamental e médio que visitam o laboratório. Utilizar o espaço do Laboratório da Anatomia para ações educativas e culturais fortalece $\mathrm{o}$ desenvolvimento de atividades de ensino e extensão do mesmo e contribui para o desenvolvimento de estudos e inovações pedagógicas que objetivam a superação da deficiência escolar local.

O aluno de escolas públicas e privadas, do ensino fundamental e médio da cidade de Jataí-Goiás, tem acesso aos conteúdos teóricos relacionados à anatomia, muitas vezes sem poder vincular esses conteúdos à prática, o que foi possível através da execução desta proposta. A visitação facilitou a compreensão dos conteúdos de anatomia e ciências, ministrados no ensino fundamental e médio, despertando uma possível escolha profissional, instigando o indivíduo a conhecer e respeitar o ensino da anatomia nas suas diversas áreas.

Para isso buscamos dinamizar o atendimento aos integrantes do ensino fundamental e médio de instituições que não possuem um acervo de peças anatômicas, para promover a 
popularização do conhecimento em anatomia através de visitas de escolas públicas e privadas ao Laboratório de Anatomia do Campus Jataí/UFG. Com isso possibilitou o acesso do alunado ao acervo, estimulando o conhecimento de anatomia. Contudo, os alunos visitantes podem vivenciar na prática aquilo que é ministrado em sala de aula, permitindo abrir espaços para discussões e sanar dúvidas sobre o conteúdo visto apenas na teoria; além de poder despertar interesse sobre os cursos oferecidos na instituição e contato com profissionais formados nas áreas das Ciências da Saúde e Ciências Agrárias, e assim verificando, através do questionário, o impacto da visita no aprendizado e na escolha profissional.

\section{METODOLOGIA}

O Laboratório de Anatomia, localizado dentro da Cidade Universitária José Cruciano na Universidade Federal de Goiás/Regional Jataí, é composto pelo Laboratório de Anatomia Veterinária, Humana e Comparada e por um Museu do Cerrado. Foram utilizadas peças que compõem o acervo em aulas e de exposição do museu, peças essas feitas por diversas técnicas como: fixação, taxidermia, maceração, conservação úmida, insuflação e algumas peças da anatomia humana com utilização restrita para determinadas idades.

Os alunos conheceram o museu onde assistiram a uma pequena palestra sobre as técnicas de conservação dos animais taxidermizados, seguindo para o Laboratório de Anatomia Veterinária, no qual foi possível ver peças utilizadas para aulas práticas e os métodos de arquivamento. No Laboratório de Anatomia Humana foi ministrada uma pequena aula dos conteúdos solicitados pelos professores de Ciências e Biologia.

O projeto visou a atender a mais de 600 alunos, cursando séries de $6^{\circ}$ ao $9^{\circ}$ ano do ensino fundamental, turmas de $1^{\circ}$ a $3^{\circ}$ ano do ensino médio e EJA de 46 escolas de 9 cidades no sudoeste goiano; dentre essas, sendo vinte seis escolas estaduais dos municípios de Aparecida do Rio Doce, Aporé, Caçu, Chapadão do céu, Itajá, Itarumã, Lagoa Santa, Serranópolis e Jataí. Além de doze escolas municipais da cidade de Jataí, sendo uma do povoado da Estância, que atende alunos da zona rural e urbana e oito escolas particulares também do município de Jataí.

Para o desenvolvimento do folder encaminhado às escolas da região, foram usados materiais de captura de imagem e fotografia da marca Sony modelo $\alpha 200$, e na produção de 


\section{Vol, 12, N. 22016}

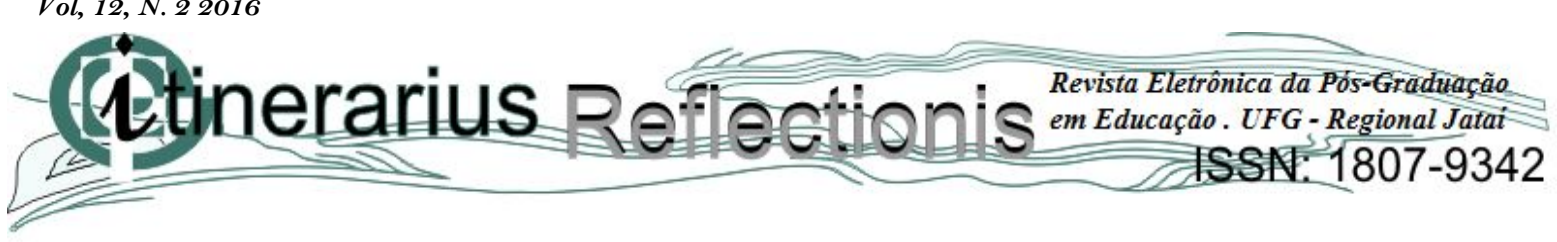

mídia digital utilizou-se ferramentas como Corel Draw, Adobe Photoshop e Adobe Ilustrador, tentando estar dentro das regras e conceitos usados por profissionais de marketing.

Também foi elaborado um questionário que visava a entender, através do relato dos alunos, o quanto a visita os auxiliou na compreensão dos conteúdos ministrados pelos professores do ensino fundamental e médio. As perguntas do questionário a respeito da visita ao Laboratório, foram sucintas, como por exemplo: se já havia visitado outra instituição ou conhecia um Laboratório de Anatomia, se a visita ao Laboratório contribuiu para esclarecer alguma dúvida pessoal e se esta mudou sua escolha profissional ou a reforçou.

Após a visita, os alunos responderam a esse questionário que visou entender, através de relato, o quanto a visita os auxiliou na compreensão dos conteúdos ministrados em Ciência e Biologia, que na maioria das vezes é ensinado apenas de forma teórica, e se o conhecimento prático apresentado no laboratório ajudou a despertar o interesse ou elucidou dúvidas sobre as profissões e cursos nas áreas da Saúde e Ciências Agrárias oferecidos pela Regional Jataí. Os questionários também nos ajudaram a avaliar e selecionar métodos que aprimorem a visita do aluno ao laboratório, através de dicas e sugestões.

Com os contatos de e-mail das escolas da região, fornecidos pelas secretarias de educação e do contato direto com as instituições do município de Jataí, foi encaminhado o Fôlder, contendo informações sobre como proceder os agendamentos de horários disponíveis para visitas.

\section{RESULTADOS}

Foi encaminhado e-mails às escolas públicas e privadas, anexado ao fôlder (Figura1) com as informações necessárias para a o agendamento da visita. 


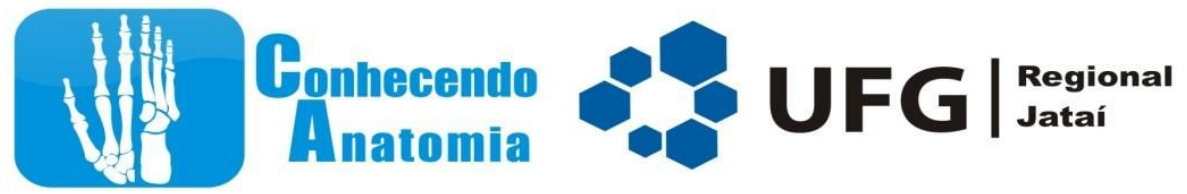

\section{Venha conhecer o nosso Laborátorio}

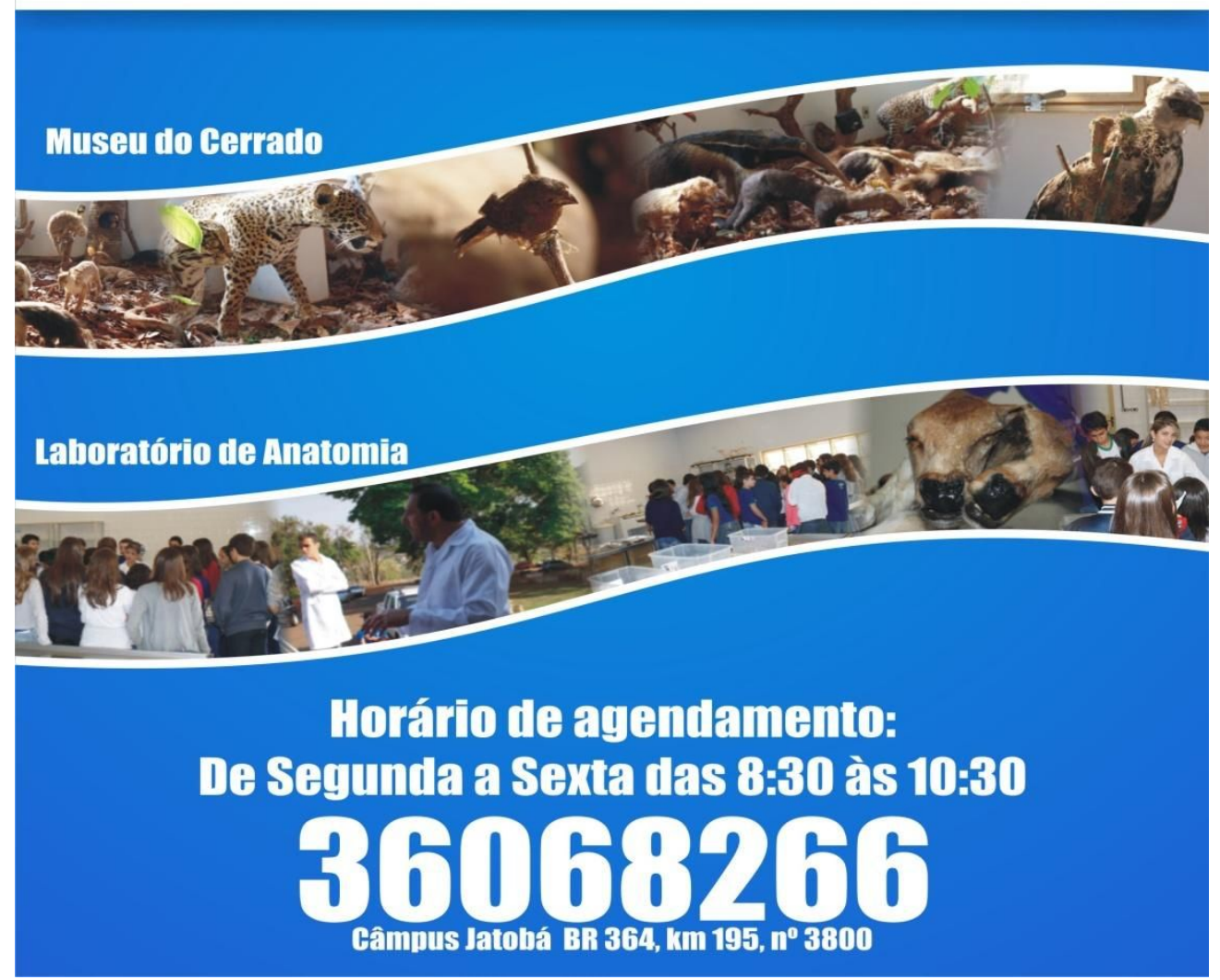

Fonte: LANVET, 2014

No período de setembro de 2014 a junho de 2015, tivemos a visita de quatro escolas, totalizando 173 alunos de ambos os sexos, com idade entre 12 a 14 anos, cursando o $7^{\circ}$ e $8^{\circ}$ anos, os quais responderam nossos questionários que buscavam verificar as perspectivas futuras do aluno secundarista em sua escolha profissional, na universidade e quanto a visita ao laboratório influenciou em seu conhecimento.

Com os dados obtidos através do questionário, podemos observar no gráfico 1, um pouco do cenário na educação atual no sentido dos conteúdos práticos nas escolas onde $66,4 \%$ 
dos alunos nunca haviam visitado nenhuma outra instituição de ensino, além da qual estudavam, sendo que mesmo em escolas públicas o percentual chega a $67,82 \%$. E quando se fala em visitas a laboratórios de anatomia, a situação é ainda mais discrepante. No total de alunos, 91,9\% não tinham feito visitas, e ainda mais preocupante nas escolas públicas onde o percentual chega a 96\%, tendo em vista o caráter público da instituição e seu fácil acesso. Parcerias como essa são imprescindíveis na tentativa de reduzir as falhas no ensino fundamental e médio.

Gráfico 1: Visitou outra instituição e conhecia algum Laboratório de Anatomia

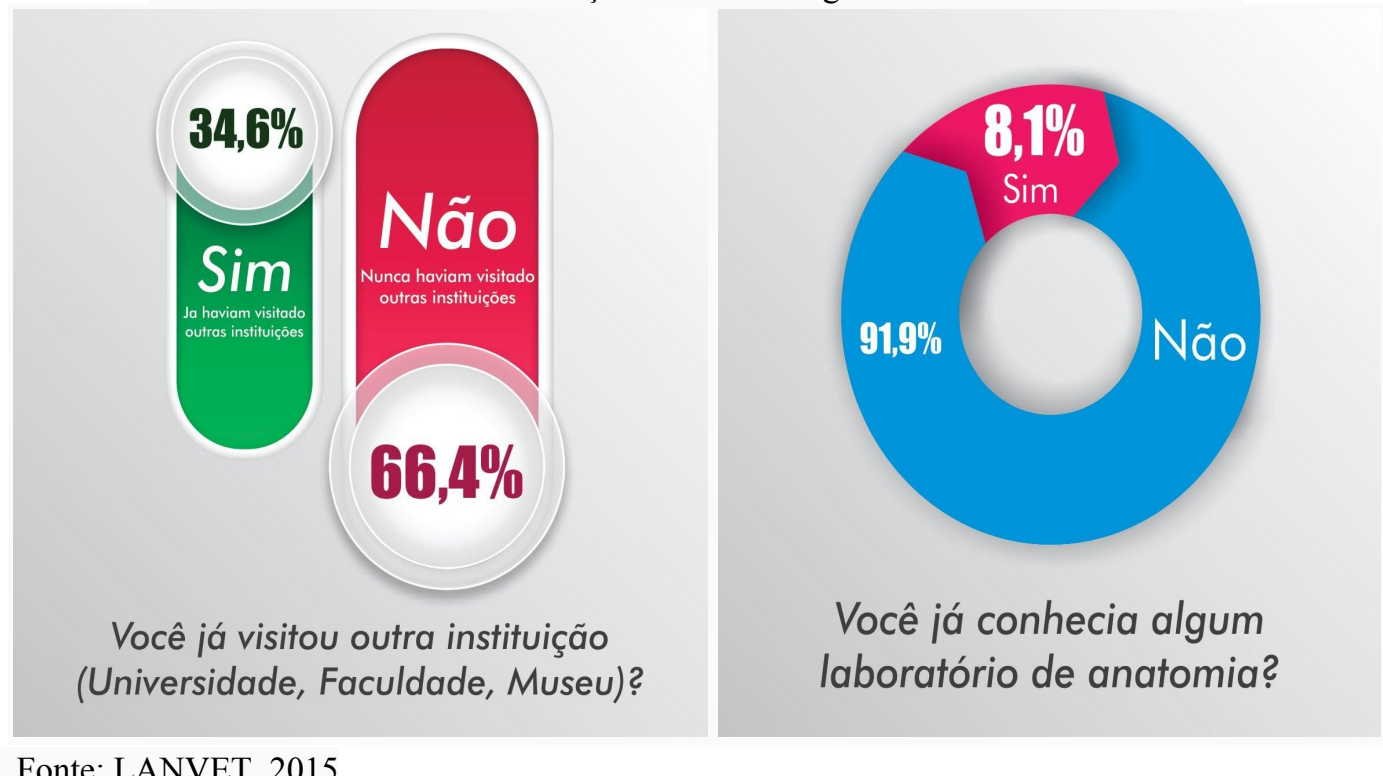

Fonte: LANVET, 2015

Sobre as perguntas do questionário, demonstradas no gráfico 2 , para $60 \%$ dos alunos a visita veio esclarecer dúvidas pessoais sobre os conteúdos administrados nas suas respectivas escolas, sendo que, $56 \%$ desses tinham alguma escolha profissional.

Gráfico 2: Esclarecer dúvidas pessoais e escolha profissional 


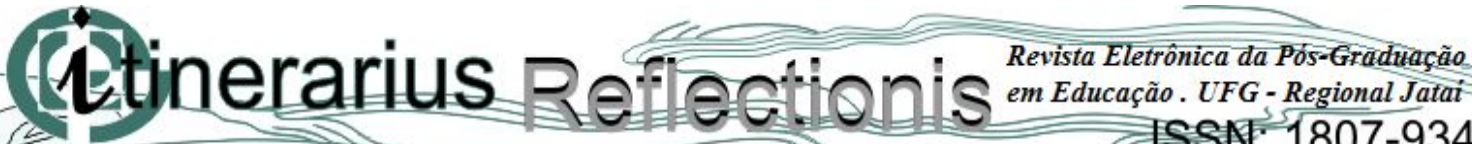

Esta visita ao laboratório de anatomia contribui para esclarecer alguma duvida pessoal?

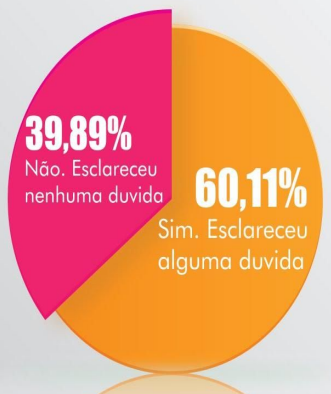

Fonte: LANVET, 2015

Das escolhas profissionais, podemos observar no gráfico 3 que 13,29\% mudaram sua escolha profissional e 41,04\% afirmaram que a visita ao laboratório reforçou a escolha profissional.

Gráfico 3: Quanto a visita ao laboratório influenciou na escolha profissional 
QUANTO A VISITA AO LABORATÓRIO

ESCOLHA UMA DAS OPÇÕES

MUDOU SUA ESCOLHA

PROFISSIONAL

23 ALUNOS

REFORÇOU ESCOLHA

QUE JÁ POSSUIA

71 ALUNOS

NÃO FEZ DIFERENÇA

EM SUA ESCOLHA

48 ALUNOS

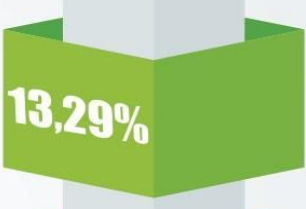

NÃO QUER FAZER
ESCOLHA AINDA

31 ALUNOS
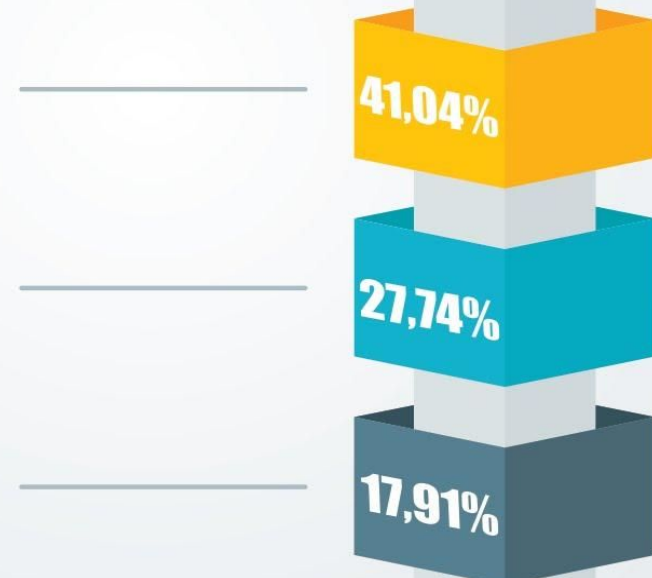

Fonte: LANVET, 2015

\section{DISCUSSÃO}

Uma grande dificuldade no processo de execução do projeto são as custas do transporte desses alunos até a universidade. Como não temos recursos para custear essa despesa, ela é feita pelas escolas com a ajuda dos alunos e professores responsáveis, justificando o baixo número de escolas visitantes. Mas o que podemos observar até o momento é a satisfação das escolas que participaram do projeto, através de uma melhor compreensão dos conteúdos de anatomia e ciências, ministrados no ensino fundamental e médio.

Em uma proposta semelhante a nossa, Evaristo et al., 2013, com o intuito de contribuir no processo de ensino-aprendizagem, esclarecendo dúvidas e curiosidades, como também, permitindo o contato de alunos e professores com material cadavérico humano, abre as portas do Laboratório de Anatomia da Universidade Federal Rural de Pernambuco, e verifica uma 


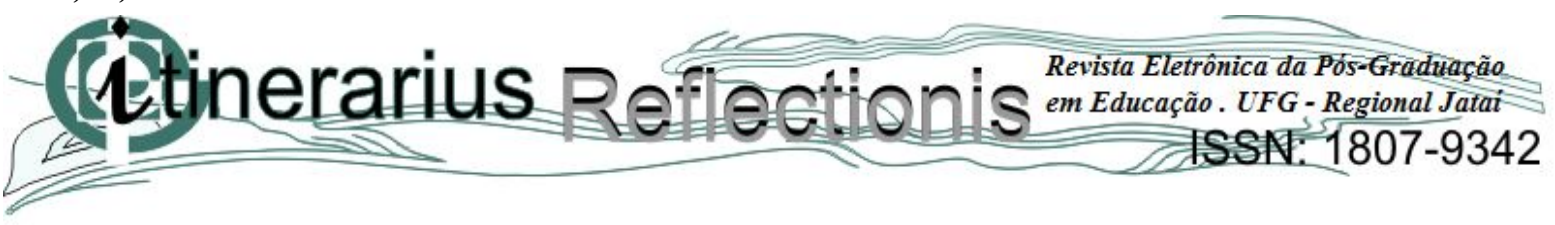

contribuição no conhecimento, favorecendo o desenvolvimento intelectual e social dos cidadãos.

Para Coltro et al., 2007, levar os alunos das escolas a conhecerem as instalações da Instituição e participarem de atividades relacionadas com laboratórios, entrando em contato com ciências e os vários conceitos de Anatomia, faz despertar a importância da universidade em suas vidas. E também proporciona aos acadêmicos desfrutar de um exercício importante de cidadania, que é a disseminação do conhecimento, buscando contribuir na formação do cidadão através da educação.

Nesse estudo pode-se observar satisfação, curiosidade e interesse dos alunos, o que vem a ser confirmado por Menezes e Cordova, 2012, em que afirmam que as atividades que buscam o interesse dos alunos contribuem ativamente na melhorio do ensino. O segredo está em adaptar sua estratégia de acordo com a realidade escolar e a realidade do alunado em questão.

Segundo Veneri et al (2008) a atividade lúdica possibilita os alunos a expressar mais entusiasmo, com melhor participação nas aulas e atividades propostas, tornando dinâmico e interativo o aprendizado. Haja vista que esses alunos ficam extremamente satisfeitos ao visitar os laboratórios. Ações políticas as quais auxiliam a educação escolar liberam os estudantes da ignorância e de uma visão espontânea do real, podendo ter mais um patamar da consciência de si como sujeitos e de seus direitos como cidadãos (CURY, 2010).

O direito à educação escolar é fundamental (MARSHALL, 1967; PRZEWORSKI, 1989; BOBBIO, 1992), essa é uma constatação que pode ser considerada como historicamente recente, sobretudo, em termos legais (CURY, 2000). No entanto, o acesso à educação e uma educação de qualidade apresentam-se distantes, pois a busca por um ensino de qualidade é uma árdua batalha que deve ser travada em várias frentes. Trabalhos como esse mostram a importância da universidade socializar o seu espaço para garantir uma melhor qualidade na educação tanto no ensino fundamental e médio, quanto no ensino superior, sabendo que um aluno que chega melhor preparado tem maior facilidade em concluir a graduação. 
Para uma educação de qualidade as variáveis de processo são consideradas fundamentais (ROSSBACH , CLIFFORD E HARMS, 1991; TIETZE, LEAL, ROSSBACH, 1998), e essa ação fundamenta as variáveis em estrutura. Porém segundo Rossbach , Clifford E Harms, 1991; Tietze, Leal, Rossbach, 1998, estes dois tipos de características não devem ser vistos de forma isolada pois interagem dinamicamente.

Através da extensão, a universidade influencia e também é influenciada pela comunidade, possibilitando uma troca de valores entre ambos. A extensão universitária leva conhecimentos e assistência à comunidade, bem como aprende com o saber dessas.(SCHEIDEMANTEl et al. 2004). De maneira que o resultado desta ação nos motiva a continuar tal intercâmbio, auxiliando no desenvolvimento da sociedade como um todo.

\section{CONSIDERAÇÕES FINAIS}

A importância da universidade de socializar os espaços, o acervo e os conteúdos com a comunidade da região pode facilitar o entendimento e a aprendizagem dos alunos, além de contribuir para o desenvolvimento de estudos e inovações pedagógicas que objetivaram melhorar e dinamizar o atendimento aos integrantes do ensino fundamental e médio de instituições que não possuem um acervo de peças anatômicas.

\section{REFERÊNCIAS}

BOBBIO, N. A Era dos Direitos. Campus: Rio de Janeiro, 1992. p. 49-65.

BORGES, G. L. A. Seres vivos e ambiente: levantamento e análise de novos materiais didáticos para o ensino de ciências e biologia. In: Encontro perspectivas do ensino de Biologia, 6. 1997, São Paulo. Coletânea do $6^{\circ}$ Encontro de perspectivas do ensino de Biologia, São Paulo; 2000. p.49-52

COLTRO, M. F. A.; LAAT, F. A; SANTOS, G. R. O projeto de extensão: "Da escola à Universidade" na cidade de Irati. Revista Mackenzie de Educação Física e Esporte. v. 6, n. 2, p. 185-189. 2007.

CRUZ, R.; LEITE, S.; ORECCHIO, L. A. Experimentos de ciências em microescala: corpo humano: 1. grau. Scipione, 1996. p.05-38. 


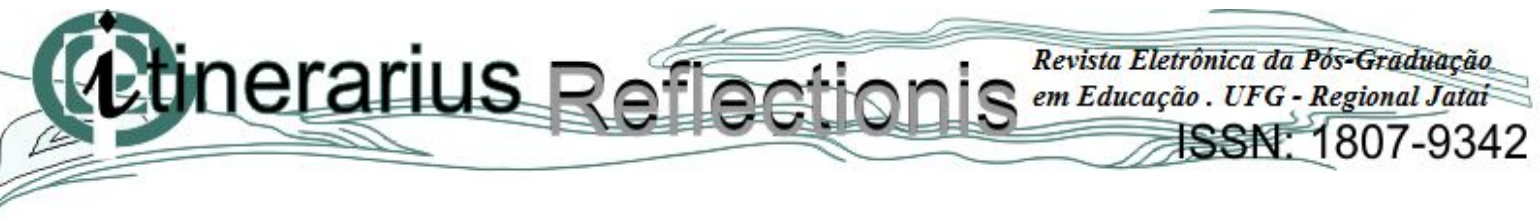

CRYER, D. Defining and assessing early childhood program quality. the annals of the american academy of political and social science, v. 563, n. 1, p. 39-55, 1999.

CURY, C. R. J. A Educação Como Desafio na Ordem Jurídica. In: LOPES, E. M. T.; FARIA FILHO, L. M.; VEIGA, C. G. 500 anos de educação no Brasil. Belo Horizonte: Autêntica, 2000. p. 567-584.

CURY, C. R. J. Qualidade em educação. Nuances: estudos sobre Educação, v. 17, n. 18, p. 15-31. 2010.

EVARISTO, D. C. S.; MENEZES T.M.; SILVA, D M S; SILVA, K R. S.; CRUZ, J. E. S.; BRITO, V. C. Anatomia Humana para Todos: Contribuindo Para a Compreensão Do Corpo Humano. In: XIII JORNADA DE ENSINO, PESQUISA E EXTENSÃO - JEPEX 2013 UFRPE:

Recife.

Disponível

em:

$\leq$ http://www.eventosufrpe.com.br/2013/cd/resumos/R0720-1.pdf $>$. Acessado em 02 de abril de 2016 .

FERREIRA, J. R. Uma Reflexão Sobre O lugar da extensão universitária na grade curricular dos cursos de graduação. Arquivos do Museu Dinâmico Interdisciplinar, v. 9, n. 2, p. 55-60, 2005.

KRASILCHIK, M. Prática de ensino de biologia. 4. ed. SãoPaulo: EdUSP, 2004. p.10-66.

MADRUGA, J. A. G. Desenvolvimento psicológico e educação. Porto Alegre: Artes Médicas; 1996. p. 68-73.

MELO, S. R.; RIBEIRO, A. M.; ESQUARCINI, S. D. G.; CONEGERO, C. I.; STABILLE, S. R. Preparação de material biológico para aulas teórico-práticas de Biologia no Ensino Fundamental e Médio. Arq Apadec. v. 6, n. 2, p. 45-6, 2002.

MENEZES, H.; BARBOSA. de; CORDOVA, B. C. Ludicidade aplicada ao ensino de ciências: anatomia em foco. Faculdade de Ciências da Educação e Saúde - FACES, Curso de Licenciatura em Ciências Biológicas. Brasília. 2012. Disponível em: http://repositorio.uniceub.br/bitstream/235/5956/1/21039790.pdf. Acesso em janeiro de 2016. Ministério da Educação. (2000). A educação pré-escolar e os cuidados para a Infância em Portugal: Estudo Temático da OCDE. Lisboa: Ministério da Educação:Departamento da Educação Básica. Disponível em: 


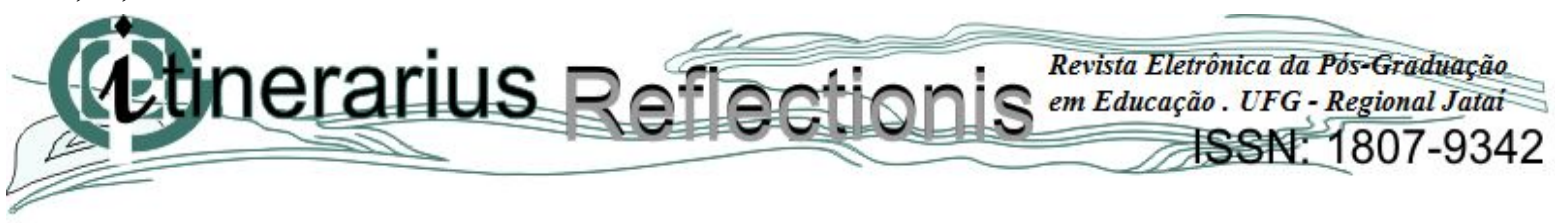

$<\underline{\text { http://www.oei.es/inicial/articulos/educacao_preescolar_portugal2.pdf }>}$. Acesso em novembro de 2015.

MOLINARI, S. L.; MONTEIRO, A. S.; MIRANDA-NETO, M. H. Práticas para abordar o tema sistema esquelético. Arq Apadec. v. 3, n. 2, p. 36-40, 1999.

OLIVEIRA, P. T. S. Ensino do corpo humano: abordagens dos professores de ciências no $8^{\circ}$ ano do ensino fundamental em escolas estaduais de Planaltina de Goiás. 2011. 42 f. Trabalho de conclusão de curso (Licenciatura em Ciências Naturais) - Universidade de Brasília, Brasília, 2011

Disponível

em:

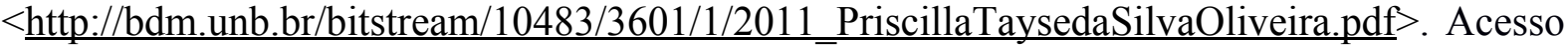
em outubro de 2015 .

PRZEWORSKI, A. Capitalismo e social-democracia. São Paulo: Cia. das Letras. Cap. 1: A social-democracia como um fenômeno histórico, 1989. p. 19- 65.

REIS, R.H. A extensão como prática acadêmica e sua indissociabilidade ao ensino e a pesquisa. Revista de Extensão Universitária. v.1, n. 3. p. 43-45. 1997.

ROSSBACH, H.; CLIFFORD, R.; HARMS, T. Dimensions of learning environments: cross national evaluation of the early childhood environment rating scale. In: AERA Annual Conference, Chicago. 1991.

SCHEIDEMANTEL, S. E.; KLEIN, R.; TEIXEIRA, L. I. A importância da extensão universitária: o projeto construir. In: ANAIS DO $2^{\circ}$ CONGRESSO BRASILEIRO DE EXTENSÃO UNIVERSITÁRIA, BELO HORIZONTE. 2004. Sep 12-15; Belo Horizonte: UFMG-seção Direitos Humanos; 2004. Disponível em:

https://www.ufmg.br/congrext/Direitos/area de direitos humanos.html. Acesso em novenbro de 2015 .

SILVA, F. M. P. Da literatura, do corpo e do corpo na literatura: Derrida, Deleuze e monstros do Renascimento. 2007. 187 f. Dissertação (Mestrado) - Universidade de Évora, Évora, 2007. Disponível em: <http://criticanarede.com/teses/deleuze.pdf>. Acesso em 17 novembro 2015. 
TABOLKA, C. C; GROTTO, E. M. B. Universidade e Escola: Diferentes culturas que se encontram em diferentes momentos, universidade regional integrada do alto do Uruguai e das missões, 2012, $\quad$ p. 14-18. Disponível em: http://www.fw.uri.br/NewArquivos/publicacoes/publicacoesarquivos//158.pdf. Acesso em janeiro de 2016.

TEIXEIRA, L. R. M. Dificuldades e erros na aprendizagem da Matemática. ENCONTRO PAUlista de EdUCAÇÃo MATEMÁTICA. 7, 2004, p. 1-14. São Paulo. Anais... São Paulo: SBEM, 2004.

TIETZE, W. et al. Assessing quality characteristics of center-based early childhood environments in Germany and Portugal: a cross-national study. european journal of psychology of education, v. 13, n. 2, p. 283-298, 1998.

VENERI, F. H.; ZANONI, L. B.; POSIGNOLO, L. F.; FRANZOL, V. Passatempo de anatomia humana: as possibilidades de um material Pedagógico alternativo. Anais do $6^{\circ}$ Amostra Acadêmica da UNIMEP. Disponível em:

http://www.unimep.br/phpg/mostraacademica/anais/6mostra/4/335.pdf. Acesso em novembro de 2015 .

VIGOTSKI, L. S. Pensamento e linguagem. São Paulo: Cortez, 2000.

ZUANON, A. C. A; DINIZ, RES. O ensino de Biologia e a participação dos alunos em "atividades de docência": uma proposta metodológica. In: NARDI, R.; BASTOS, F.; DINIZ, R. E. S. (Orgs). Pesquisas em ensino de ciências: contribuições para formação de professores, p. 111-131, 2004. 